\title{
Creativity Self-Efficacy Scale as a Predictor for Classroom Behavior in a Chinese Student Context
}

\author{
Ai-Girl Tan ${ }^{*}, 1, J_{0 e} \mathrm{Li}^{2}$ and Jerome Rotgans ${ }^{3}$ \\ ${ }^{I}$ Nanyang Technological University, Singapore and Kansai Gaidai University, Japan \\ ${ }^{2}$ Ludwig-Maximilians-University of Munich, Germany \\ ${ }^{3}$ National Institute of Education, Singapore
}

\begin{abstract}
Five hundred and forty five Chinese students participated in study aimed to examine multi-dimensionality of creativity self-efficacy and its contextual (i.e., classroom environment) correlates. Nearly all aspects in the What Happens in the Classroom Scale (e.g., student cohesiveness, investigation, and task orientation) were found to have significant, positive correlations with all subscales of creativity self-efficacy (e.g., idea generation, tolerance of ambiguity). Creativity self-efficacy was a predictor of classroom behavior.
\end{abstract}

Keywords: Creativity self-efficacy, chinese, classroom behavior.

\section{INTRODUCTION}

Creativity self-efficacy refers to "the belief one has the ability to produce creative outcomes" [1]. It is a form of selfevaluation that influences decisions regarding the amount of effort and the persistence level undertaken when encountering challenges creatively [2]. Self-efficacy belief is a major driving force for creative actions [3]. Growing empirical evidence has manifested direct or reciprocal links between efficacy beliefs and creativity-related outcomes [4]. Carmeli and Schaubroeck [5] reported the influence of an individual's perceived expectations of their work supervisor, customers, and family on the individual's creative involvement at work. The finding is consistent with that of McNatt and Judge [6]: Deliberately raising expectations led to sustained higher performance only among self-efficacious individuals.

In Tierney and Farmer's [1] study, 584 (mostly blue collar) and 158 (white-collar) employees from two firms participated in the survey. Job tenure, job self-efficacy, supervisor behavior and job complexity contributed to creativity self-efficacy beliefs. In addition, job self-efficacy was found to be the strong predictor of creative self-efficacy. The creative performance among white-collar employees was largely efficacy driven. Creativity self-efficacy predicted creative performance beyond the predictive effects of job self-efficacy.

Choi's [7] study was based on longitudinal multi-source data from 430 students on an introductory business course at a North American business school. In the survey, the underlying psychological processes included two aspects: Creative self-efficacy and creative intention. Findings from a confirmatory structural equation modeling (SEM) analysis

*Address correspondence to this author at the Nanyang Technological University, 1 Nanyang Walk, 637616, Singapore;

Tel: (65)-6790-3184; E-mail: aigirl.tan@nie.edu.sg supported all hypotheses of the study. The study concluded that creative self-efficacy and creative intention mediate the effects of individual characteristics (e.g., personality and creative ability) and social influences (e.g., supportive leadership and open group climate) on creative performance.

The study addressed two common conceptual pitfalls in creativity research in the classroom, namely the narrow view of creativity (e.g., viewing creativity as synonymous with originality, see Beghetto \& Kaufman [8]), and focusing too little on the role of creativity self-efficacy and classroom behavior. Tan [9] conceptualizes creativity as a multidimensional and multi-systemic construct. Our conception of the construct of creativity self-efficacy includes creativity self-efficacy related to creativity relevant processes, creativity self-efficacy related to domain-relevant processes, and creativity self-efficacy related to task motivation. Elsewhere we have reported our view of multidimensional conception of creativity self-efficacy based on the componential theory of creativity $[9,10]$ and theory of self-efficacy $[2,3]$. Briefly, in the context of teaching and learning, creativity includes creativity relevant processes, teaching and learning processes, as well as emotional and motivational processes. Accordingly, creativity self-efficacy for learning comprises multiple components of self-efficacy: efficacies related to creativity-relevant, teaching and learning relevant, and emotional or motivational processes. With reference to theory of self-efficacy [3] we constructed the items of creativity self-efficacy for the learners. We developed a multidimensional creativity self-efficacy scale for the learners (MCSE) which incorporated some processes of creativity of the componential theory of creativity [10]: Idea generation, concentration, working style, independence, and tolerance of ambiguity. Our study aims to investigate the multidimensional construct of creativity self-efficacy and its correlates with students' perceived classroom behavior. We employed a self reported classroom behaviors measure: What is happening in class (WIHIC) scale (to be reviewed further in the method session) to find out students' views of 
their own engagement in learning with the other pupils and teachers. We hypothesized that the multidimensional creativity self-efficacy scale (MCSE) is able to show positive associations with the various components of students' views of classroom behavior. The MCSE can be a good measure to find out if creativity self-efficacy is a predictor of students' perceived classroom behavior.

Teachers, in many ways, resemble the leaders in organizations. Open, participative, non-controlling and supportive leaders engender more creative outcomes than directive and controlling leaders [11]. Teachers who accept and encourage creative thinking, tolerate dissent, encourage students to trust their own judgment and emphasize that everyone is capable of creativity will stimulate creative thinking [12].

Shapiro [13] suggests that the proper selection of classroom activities can create a positive classroom climate. Treffinger and Isaksen [14] propose classroom activities that are related to the discovery process, and thus can be used to enhance creativity. Ponte and Martos [15] claim that mathematical investigations share common aspects with other kinds of problem solving activities. They involve complex thinking processes and require a high involvement and a creative stand from the student. A study of Segurado [16] gave students in grade six an investigatory task to see how they would react. He concluded that by doing investigations, students were able to approach the tasks and move in the direction of becoming confident in expanding their abilities to solve and formulate problems, and to communicate and reason mathematically.

Involvement includes participation in the class and in the topic. It is recommended as a strategy for establishing classroom environment conductive to creative thinking [17]. According to the study of Butler [18], task-involvement is beneficial to factors such as interest, enjoyment, effort, and the assessment and improvement of past performance. Maintaining interest or task involvement seems necessary for effective utilization of informational cues or challenges to perform better.

Shaughnessy [19] recommends an educational climate consisting of communication, consensus, consistency, clarity, coherence, consideration, community, cohesiveness, commitment, concern, care and cooperation. Moore [20] tested his hypothesis of positive effects of cohesion on the creativity of small groups. The participants in the study were students in social science classes at an urban university's branch campus primarily attended by arts students. Results showed that high cohesion groups had higher creativity scores than individuals working alone and low cohesion groups.

Hsiao, Chang, and Huang [21] attempted to explore the effectiveness of cooperative learning in creative production of undergraduate project work. The participants of the study were 65 senior students from the department of industrial education and technology in Hong Kong. The instruments of this study consisted of the verbal and non-verbal forms of the Torrance Test of Creative Thinking, the idea-design creativity test and the self-designed questionnaire of satisfaction of the cooperative learning. Both the teachers and the students enjoyed cooperative learning, and thought it would improve the abilities of cognitive, psychomotor, affective and creativity domains.

Task orientation is often associated with the concept of motivation [10]. According to the theory of achievement goal orientation, task-oriented students are primarily interested in attaining mastery and improving their knowledge or competence. For these students, learning the material is seen as an end in itself. Suárez, Riveiro Cabanach and Arias [22] investigated multiple-goal pursuit and its relation to cognitive, self-regulatory and motivational strategies. They found that only students who reported high task orientation tended to report frequent use of cognitive and self-regulatory strategies. Accordingly, the relationship between creativity self-efficacy and classroom behavior, based on the review, is examined with reference to the following hypothesis: Perceived supportive environments (i.e., investigation, task orientation, student cohesiveness, involvement, equity and cooperation) have a positive relationship with creativity self-efficacy.

\section{METHOD}

\section{Participants}

A total of 545 students mainly from six secondary schools in Shanghai participated in this study. They consisted of $245(45 \%)$ males and $300(55 \%)$ females. The participants were between 12 and 19 years old $(M=14.7$, $S D=1.73$ ). They completed the survey online.

\section{Materials}

Multidimensional Creativity Self-efficacy Scale (MCSE). The MCSE is a multi-dimensional creativity self-efficacy scale that was developed by Tan [23] and consists of five subscales: (1) Idea generation (seven items, e.g., "I am good at combining existing ideas"), (2) Concentration (six items, e.g., "I can focus on doing something valuable"), (3) Tolerance of ambiguity (three items, e.g., "I can delay judgment when coming up with ideas"), (4) Independence (six items, e.g., "I can work on task that allow for my evaluation"), and (5) Working style (seven items, e.g., "I am willing to master knowledge I need for creative tasks"). All items were assessed on a 5-point Likert scale: 1 (strongly disagree), 2 (disagree), 3 (neutral), 4 (agree), and 5 (strongly agree). The construct validity of the instrument in the Chinese context was established by means of confirmatory factor analysis, or CFA. The results revealed that the data adequately fitted the measurement model: Chisquare $=893.47, \mathrm{df}=308, p<.01, \mathrm{CFA}=.93$, and RMSEA $=.06$. The reliability of the instrument was established by means of Hancock's coefficient $H$ for each scale of the MCSE. The coefficient $H$ is a construct reliability measure for latent variable systems that represents an adequate alternative to the conventional Cronbach's alpha. According to Hancock and Mueller [24] the usefulness of Cronbach's alpha and related reliability measures is limited to assessing composite scales formed from a construct's indicators, rather than assessing the reliability of the latent construct itself as reflected by its indicators. The coefficient $H$ is the squared correlation between a latent construct and the optimum linear composite formed by its indicators. Unlike other reliability measures the coefficient $H$ is never less than the best indicator's reliability. In other words, a factor inferred from 
multiple indicator variables is never less reliable than the best single indicator alone. The coefficient $H$ ranged from .73 (idea generation) to .89 (independence) with an average of .85 (for the record, average Cronbach's alpha $=.84$ ). These values are indicative of adequate validity and reliability of the MCSE.

Self reported classroom behaviors. In order to measure students' perceived class room behaviors the What is happening in class (WIHIC) scale [25] was administered. The WIHIC consists of 56 items over seven subscales: (1) Student cohesiveness (e.g., "I know other students in this class."), (2) Involvement (e.g., "I explain my ideas to other students"), (3) Investigation (e.g., "I find out answers to questions by doing investigations."), (4) Task orientation (e.g., "I know how much work I have to do."), (5) Cooperation (e.g., "I cooperate with other students on class activities"), (6) Equity (e.g., "I get the same opportunity to contribute to class discussion as other students."), and (7) Teacher support (e.g., "The teacher moves about the class to talk with me."). All items were assessed on a 5-point Likert scale: 1 (strongly disagree), 2 (disagree), 3 (neutral), 4 (agree), and 5 (strongly agree). The validity and reliability of the scale was established elsewhere [26]. For our sample, we assessed the reliability by means of Cronbach's alpha, which ranged from .85 (orientation) to .92 (teacher support and investigation) with an average of .89. These values are similar to the values reported by Aldridge and Fraser [25] in their validation study of the WIHIC. For the purpose of this study we combined all seven subscales to an aggregate value representing students overall classroom behaviors.

\section{Translation and Back-translation}

The multidimensional creativity self-efficacy scale were translated into the Chinese language and back translated into the English language independently by two bilingual persons. To ensure equivalence in meaning, the translated and back-translated versions of the scales were compared. Expressions of items that showed discrepancies in meaning were modified. For example, the item "I am good at combining the existing ideas" was back translated to "I am good at integrating the existing ideas", suggesting that the word "combine" is synonymous with "integrate". However, "integrate" can imply processes such as organizing and summarising. Consequently, the Chinese version was refined to ensure close meaning to the original version of the scale.

\section{Procedure}

The participants were students from Shanghai secondary school students. With help of the class teachers the second author got the consent from the participants who wished to take part in the study voluntarily with no additional reward. The participants provided their responses in a web-based environment. They were directed to a web-link, given a password, and were allowed to complete the questionnaire in their own pace. The participants were ensured that the information they provided would be kept confidential. Participants could only submit their responses to the questionnaires if they responded to all items. As such, there were no missing data.

\section{Analysis}

The relationship between the five subscales of the creativity self-efficacy scale and classroom behaviors was examined by means of multiple linear regression analysis. Classroom behavior was used as the dependent variable (an aggregated value was used summarizing all seven subscales and thus representing an aggregate of a variety of classroom behaviors). The five subscales of the MCSE served as the independent variables.

\section{RESULTS}

Mean, standard deviation, and correlation coefficients of all scales were computed. Table 1 summarises the results.

A multiple regression analysis was conducted to evaluate how well the five subscales of the MCSE predict students' self-reported classroom behaviors. The linear combination of the five MCSE subscales was significantly related to classroom behavior, $F(5,539)=109.10, p<.01$. The sample multiple correlation coefficient was .71, indicating that approximately $50 \%$ of the variance in classroom behavior can be accounted for by the linear combination of the five MCSE subscales. Table 2 depicts the summary of the results.

All standardized regression weights were statistically significant except for the subscale idea generation $(p=.05)$. The strongest predictors of classroom behaviors were tolerance of ambiguity $(\beta=.29, p<.01)$ and independence $(ß=.24, p<.01)$.

\section{DISCUSSION}

The study explored the multidimensional construct of creativity self-efficacy and its correlates with classroom behavior in a Chinese high school student's context. The multidimensionality of creativity self-efficacy (MCSE) was highly reliable. It comprised five subscales: Idea generation, concentration, tolerance of ambiguity, working style, independence. The MCSE was developed with reference to the componential theory of creativity [10] and procedures to construct self-efficacy items [2]. The findings of the study suggest that creativity self-efficacy which comprises multiple dimensions of creativity efficacies fits well to the theory of self-efficacy of Bandura [3] that self-beliefs exert influence on cognitive, motivational, decision-making, and affective processes of a person.

The MCSE correlated positively with all subscales of what is happening in the class: Cohesiveness, involvement, investigation, task orientation, cooperation, equity, and teacher support (Table 1). The findings of the study supported findings of previous studies: Creativity selfefficacy was positively correlated with momentary affect [27] and mastery goal- orientation [28]. The findings of the present study were also in line with the recommendation of Feldhusen and Treffinger [29], i.e., creating a climate of mutual respect and acceptance among students and between students and teachers, so that students can share, develop, and learn altogether and from one another as well as independently, being a resource provider and director, having choices and being a part of decision making. The 
Table 1. Correlation Matrix of All Subscales of the Multidimensional Creativity Self-efficacy Scale and the What is Happening in Class Scale

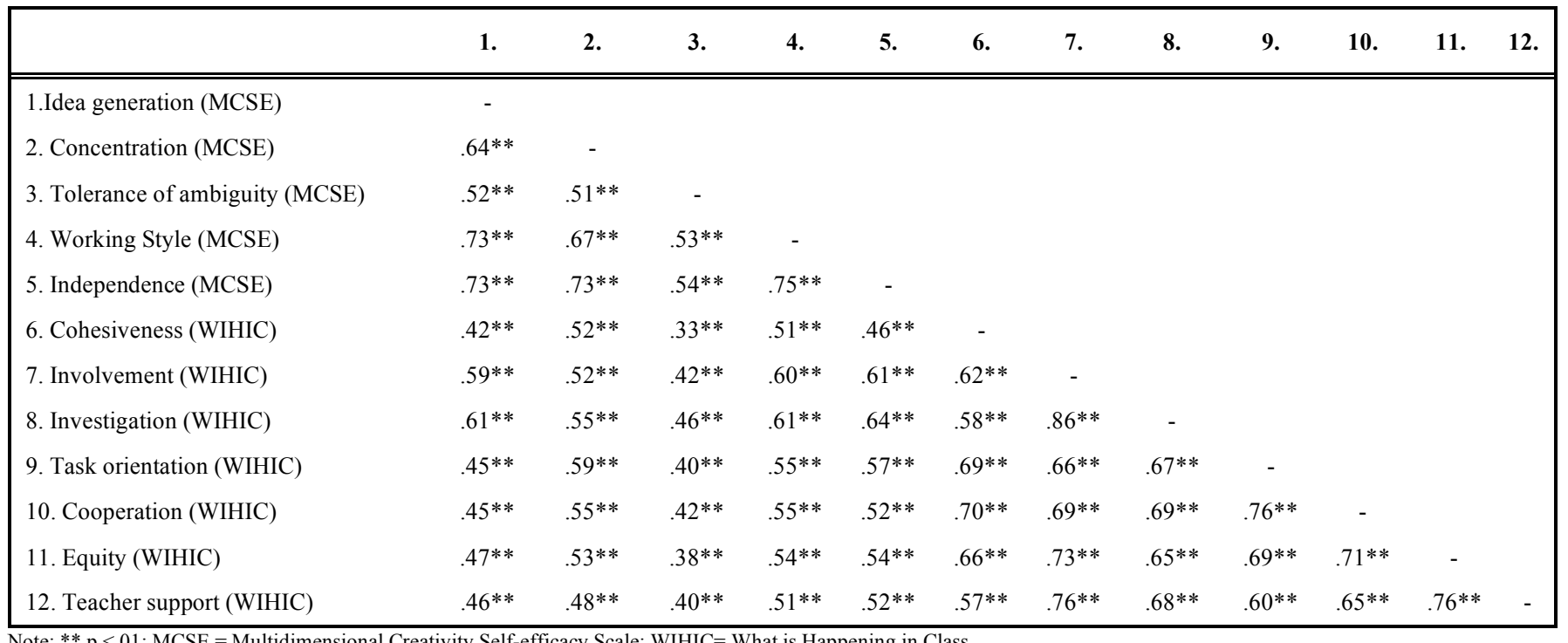

Table 2. Summary of Multiple Regression Analysis Predicting Classroom Behavior

\begin{tabular}{|c|c|c|c|c|c|}
\hline Subscale & $\boldsymbol{B}$ & $\boldsymbol{S E} \boldsymbol{B}$ & $\boldsymbol{\beta}$ & $\boldsymbol{t}$ & $\boldsymbol{p}$ \\
\hline \hline Idea generation & .08 & .12 & .10 & 1.96 & .05 \\
\hline Concentration & .06 & .04 & .08 & 2.14 & .03 \\
\hline Tolerance of ambiguity & .25 & .03 & .29 & 6.19 & $<.01$ \\
\hline Independence & .20 & .04 & .24 & 4.56 & $<.01$ \\
\hline Work style & .10 & .04 & .12 & 2.32 & .02 \\
\hline
\end{tabular}

findings were also in line with positive observation in Moore's [20] study that it is essential to provide a cohesive, investigative and task-oriented classroom environment for students to integrate information to solve problems. Cohesive climate would have positive impact in at least three ways: 1) Students will become more comfortable and tolerant in class activities. When students know each other well, they are not ashamed to speak out the seemingly "silly" ideas or afraid of being laughed at for their mistakes. It allows and encourages feedback among group members, thereby decreasing the risk of negative effects that conformity could have on a group [20]. 2) Students will be more motivated to cooperate in the group tasks, and to spark the "creativity" in each other. 3) Cohesiveness in interpersonal relationship will also be extended to common commitment to task. Teachers play an important role in building up the student cohesiveness. Teachers initiate the process of cohesiveness and act as a role model for students. Teachers promote students to confront the complex situation and find solution independently.

All MCSE subscales, except creativity efficacy for idea generation, were predictors of classroom behavior (Table 2). The findings supported Choi [7] and Tierney and Farmer [1] reports that creative self-efficacy is a good predictor of outcome behavior (e.g., job performance). They served as evidence to clarify the importance to broaden conceptions of creativity related behavior and its relations with classroom behavior. The findings of MCSE of the present study clarified specificity of creativity self-efficacy. Creativity self-efficacy for independence and tolerance of ambiguity were strong predictors of classroom behavior. Creativity self-efficacy for concentration and working style were also good predictors of classroom behavior. Educators and teachers shall broaden their conceptions of creativity related behavior such as creativity self-efficacy. They shall also adopt multidimensional conceptions of creativity self efficacy or creativity related behavior going beyond a single dimensional construct of creativity (e.g., originality [8]) or creativity efficacies (e.g., brainstorming or idea generation). Teachers and educators shall reflect upon their creativity facilitating behaviors and find out reasons for the incompatibility between creativity related behavior of the learners (e.g., creativity self-efficacy for idea generation in this study) and classroom environments. Future studies on creativity self-efficacy shall adopt various research designs (e.g., experimental or intervention study design) to explore the possible change in dimensions of creativity self-efficacy in the presence of peer and teacher feedback, achievement (success), and skill or knowledge enhancement.

\section{ACKNOWLEDGEMENT}

None declared.

\section{CONFLICT OF INTEREST}

None declared.

\section{REFERENCES}

[1] Tierney PA, Farmer SM. Creative self-efficacy: Its potential antecedents and relationship to creative performance. Acad Manage J 2002; 45: 1137-48.

[2] Bandura A. Social learning theory. New York: General Learning Press 1977.

[3] Bandura A. Self-efficacy: the exercise of control. New York: W.H. Freeman 1997

[4] Beghetto RA. Creative self-efficacy: correlates in middle and secondary students. Creat Res J 2006; 18 (4): 447-57. 
[5] Carmeli A, Schaubroeck J. The influence of leaders' and other referents' normative expectations on individual involvement in creative work. Leadership Quart 2007; 18(1): 35-48.

[6] McNatt DB, Judge TA. Boundary conditions of the Galatea effect: a field experiment and constructive replication. Acad Manage J 2004; 47: 550-65.

[7] Choi J N. Individual and contextual predictors of creative performance: the mediating role of psychological process. Creat Res J 2004; 16(2\&3): 187-99.

[8] Beghetto, RA, Kaufman, JC. The genesis of creative greatness: mini-c and the expert-performance approach. High Ability Stud 2007; 18: 59-61.

[9] Tan AG. Developing creativity self-efficacy scales. Singapore: National Institute of Education Singapore 2007 (unpublished).

[10] Amabile T. The social psychology of creativity: a componential conceptualization. J Person Soc Psychol 1983; 45(2): 357-76.

[11] Amabile T. Creativity in context. Boulder, CO: Westview Press 1996.

[12] Torrance EP, Myers, RE. Creative learning and teaching. New York: Dodd, Mead \& Company 1970.

[13] Shapiro S. Strategies that create a positive classroom climate. Clearing House 1993; 67(2): 91-7.

[14] Treffinger DJ, Isaksen SG. Creative problem solving: an introduction. Sarasota, FL: Center for Creative Learning 1992.

[15] Ponte JP, Matos JF. Cognitive processes and social interaction in mathematical investigations. In: Ponte JP, Matos JM, Fernande D, Eds. Mathematical problem solving and new information technologies: research in contexts of practice 1992; pp. 239-54.

[16] Segurndo I. O que acontece quando os alunos realizam investigac, a o matema'ticas? In: GTI, Ed. Reflectir e investigar sobre a pra'tica profissional 2002; pp. 57-73.

[17] Feldhusen JF, Treffinger DJ. Creative thinking and problem solving in gifted education. Dubuque, IA: Kendall/Hunt 1980.
[18] Butler, R. Task-involving and ego-involving properties of evaluation: effects of different feedback conditions on motivational perceptions, interest, and performance. J Educ Psychol 1987; 79: 474-82.

[19] Shaughnessy MF. The supportive educational environment for creativity. New York: Mexico: EDRS 1991.

[20] Moore RM. The positive effects of cohesion on the creativity of small groups. Int Soc Sci Rev 1997; 72(3/4): 84-93.

[21] Hsiao HC, Chang JC, Huang CY. The influence of cooperative learning on the creativity of undergraduate project work (in Chinese). Chin J Sci Educ 2000; 8(4): 395-410.

[22] Suárez, Riveiro JM, Cabanach RG, Arias AV. Multiple-goal pursuit and its relation to cognitive, self-regulatory, and motivational strategies. Br J Educ Psychol 2001; 71(4): 561-72.

[23] Tan AG. Creativity: a handbook for teachers. Singapore: World Scientific Publishing 2007.

[24] Hancock, GR, Mueller, RO. Rethinking construct reliability within latent systems. Structural equation modeling: present and future - A festschrift in honor of Karl Jöreskog R. Cudeck, S. d. Toit and D. Sörbom. Lincolnwood, IL, Scientific Software International 2001.

[25] Aldridge JM, Fraser, BJ. A cross-cultural study of classroom learning environments in Australia and Taiwan. Learn Environ Res 2000; 3: 101-34.

[26] Dorman, JP. Cross-national validation of the What Is Happening In this Class?(WIHIC) questionnaire using confirmatory factor analysis. Learn Environ Res 2003; 6(3): 231-45.

[27] Tan AG, Ho V, Ho E, Ow S. High School Students' perceived creativity self-efficacy and emotions in a service learning context. Int J Creat Problem Solving 2008; 18(2): 115-26.

[28] Hill A, Tan AG, Kikuchi, A. International high school students' perceived creativity efficacy. Kor J Thinking Problem Solving 2008, 18(1): 105-16.

[29] Feldhusen JF, Treffinger DJ. Creative thinking and problem solving in gifted education. Dubuque, IA: Kendall/Hunt 1980.

(C) Tan et al.; Licensee Bentham Open.

This is an open access article licensed under the terms of the Creative Commons Attribution Non-Commercial License (http://creativecommons.org/licenses/by-nc/ 3.0/) which permits unrestricted, non-commercial use, distribution and reproduction in any medium, provided the work is properly cited. 